\title{
TRATADO DE LIBRE COMERCIO ENTRE PERÚ Y CANADÁ (ALCANCES Y PERSPECTIVAS)
}

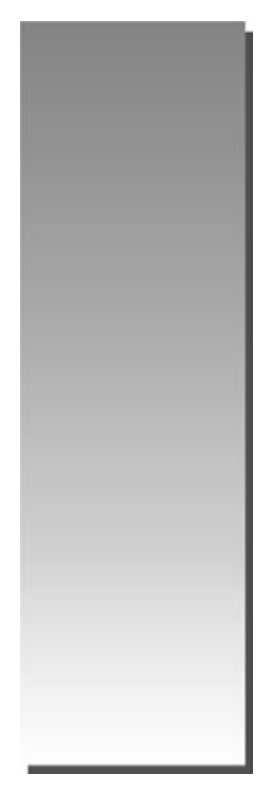

Walter Ugarte Casafranca*

E-mail:wugartec@unmsm.edu.pe

\begin{abstract}
RESUMEN
El presente artículo aborda el Tratado de Libre Comercio entre Perú y Canadá. Investiga sobre los antecedentes de la negociación, la importancia del mercado canadiense en la economía peruana y el posible impacto que ha de tener este acuerdo comercial. Incluye un análisis de los indicadores comerciales y una interpretación del acuerdo para la promoción y protección recíproca de las inversiones Perú-Canadá.
\end{abstract}

Palabras clave: TLC, Perú, Canadá, comercio internacional.

\section{ABSTRACT}

This article examines the Free Trade Agreement between Peru and Canada. Research on the background of the negotiations, the importance of the Canadian market in the Peruvian economy and the possible impact it has to have this trade agreement. It includes an analysis of the trade indicators and an interpretation of the agreement for the promotion and reciprocal protection of investments Peru-Canada.

Key words: TLC, Perú, Canada, international trade.

\footnotetext{
* Abogado, profesor de la Facultad de Ciencias Administrativas de la Universidad Nacional Mayor de San Marcos. Investigador del Área de Responsabilidad Social Empresarial. Estudios de doctorado y maestría en Administración. Conferencista internacional.
} 


\section{PRESENTACIÓN}

Con la firma en enero del 2008 del Tratado de Libre Comercio entre Perú y Canadá nos convertimos en el segundo país sudamericano, junto a Chile, que firma este tipo de acuerdo con Canadá. Según pronósticos optimistas se estima que las inversiones canadienses en los sectores mineros y gasíferos en nuestro país se incrementarán hasta alcanzar los US\$ 10,000 millones. Actualmente las inversiones de Canadá en el Perú alcanzan los US\$ 3,000 millones aproximadamente. Nuestras exportaciones hacia este país ascendieron durante el 2007 a US\$ 1,782 millones, lo cual significa un incremento del $11 \%$ con respecto al 2006.

La importancia del acuerdo para nuestra economía se refleja en el PBI de ambos países. Canadá produce el doble del Perú y ha logrado un Producto Bruto per Cápita de US\$36,000, mientras que nosotros bordeamos los US\$4,000. Recordemos que sólo el $38 \%$ de las exportaciones peruanas no tradicionales hacia Canadá corresponden al rubro agropecuario.

La economía canadiense ha tenido un desempeño creciente en las últimas décadas, el cual ha permitido a su población-que supera los 34 millones- mantener elevados estándares de vida. En términos de bienestar, el Índice de Desarrollo Humano (IDH) ha seguido una tendencia expansiva. En el año 1995 dicho índice fue de 0.935, mientras que en 2004 el indicador alcanzó un puntaje de 0.950, lo que sitúa a Canadá en el sexto puesto a nivel mundial. En el 2004, los tres componentes del IDH alcanzaron valores significativos: la esperanza de vida al nacer fue de 80.2 años, lo que le proporcionó un índice de esperanza de vida de 0.92; y el ratio de asistencia a la escuela fue de $93 \%$, lo que le permitió alcanzar un índice de educación de 0.97 .

Dentro de la política arancelaria de nuestro país, el Perú eliminará los aranceles al 94\% de las exportaciones canadienses; otro tanto hará Canadá que eliminará el $97 \%$ de aranceles a las importaciones peruanas. Las pequeñas y medianas empresas peruanas tendrán acceso al mercado canadiense porque podrán presentarse como postores a las compras estatales de dicho país pero el acuerdo entrará en vigencia posiblemente en el 2009, luego de la ratificación del mismo por los respectivos Congresos.

\section{METODOLOGÍA}

\section{Materiales}

Se utilizó el método de investigación bibliográfica y hemerográfica. Asimismo se consultaron las páginas web oficiales de Canadá y del Ministerio de Comercio Exterior y Turismo (MINCETUR). Se revisaron los resúmenes ejecutivos de las rondas de negociaciones del Tratado de Libre Comercio Perú-Canadá, así como el reporte técnico del MINCETUR en torno al acuerdo bilateral.

\section{Procedimiento}

La lectura, fichaje y análisis de los datos estadísticos sistematizó la información más importante. La interpretación cuantitativo-cualitativa de los cuadros presentados en los resúmenes ejecutivos de las rondas de negociaciones permitió establecer las conclusiones sobre la importancia del tratado con Canadá así como abrir un debate sobre los beneficios y perjuicios que este tipo de acuerdos conllevan.

\section{RESULTADOS}

La economía canadiense ha tenido un desempeño estable que ha permitido que su población mantenga elevados estándares de vida. Los factores que han permitido que la economía no presente desequilibrios han sido los elevados precios de los commodities, la expansión de la producción de aceite de petróleo y gas, y la apreciación del tipo de cambio. Así, en el 2005 con un PBI real de US\$ 812,279 millones, Canadá logró ubicarse en el noveno lugar del ranking mundial de economías según tamaño. En el siguiente cuadro se puede apreciar la composición sectorial del PBI de Canadá y Perú para el periodo 1970-2003 (ver Cuadro №1).

\section{1. Índice de Desarrollo Humano}

Recordemos que el Índice de Desarrollo Humano (IDH) es una medición elaborada por el Programa de las Naciones Unidas para el Desarrollo (PNUD) para contar con un indicador que mida el bienestar de la población. En términos de bienestar, el IDH de Canadá ha mantenido una tendencia creciente, pues en 1975 dicho índice fue de 0.870 mientras que en 1995 resultó ser de 0.935. Para el año 2004, Canadá alcanzó un puntaje de 0.9502 , situando a este país en el sexto lugar dentro de un ranking de 177 estados (ver Gráfico N.o 1). 
Cuadro No 1. Composición sectorial del PBI de Canadá y Perú, periodo 1970-2003.

\begin{tabular}{|c|c|c|c|c|c|c|c|}
\hline & 1970 & 1980 & 1990 & 2000 & 2001 & 2002 & 2003 \\
\hline \multicolumn{8}{|l|}{ CANADÁ } \\
\hline Agricultura & 4.9 & 3.7 & 3.0 & 2.0 & 2.0 & 2.0 & 2.0 \\
\hline Industria & 36.4 & 34.8 & 30.6 & 34.0 & 32.0 & 31.4 & 31.3 \\
\hline Manufactura & 0.0 & 16.3 & 17.6 & 20.0 & 18.0 & 17.5 & 17.0 \\
\hline Servicios & 58.7 & 61.5 & 66.6 & 64.0 & 65.0 & 68.6 & 68.7 \\
\hline \multicolumn{8}{|c|}{ MR Estados Unidos } \\
\hline Agricultura & 3.8 & 2.4 & 1.8 & 1.0 & 1.0 & 1.0 & 1.0 \\
\hline Industria & 34.0 & 31.2 & 25.9 & 24.0 & 23.0 & 22.0 & 22.0 \\
\hline Manufactura & 0.0 & 6.1 & 18.4 & 17.0 & 16.0 & 15.0 & 15.0 \\
\hline Servicios & 62.4 & 66.4 & 72.3 & 75.0 & 76.0 & 77.0 & 77.0 \\
\hline \multicolumn{8}{|l|}{ MR UR } \\
\hline Agricultura & 5.0 & 5.0 & 3.0 & 3.0 & 3.0 & 2.0 & 2.0 \\
\hline Industria & 38.0 & 35.0 & 30.0 & 28.0 & 28.0 & 270 & 27.0 \\
\hline Manufactura & 0.0 & 0.0 & 22.0 & 20.0 & 20.0 & 19.0 & 19.0 \\
\hline Servicios & 57.0 & 60.0 & 67.0 & 69.0 & 70.0 & 70.0 & 71.0 \\
\hline \multicolumn{8}{|l|}{ PERÚ } \\
\hline Agricultura & 12.0 & 9.8 & 9.0 & 10.0 & 10.0 & 10.0 & 10.0 \\
\hline Industria & 43.0 & 32.3 & 29.3 & 30.0 & 29.0 & 30.0 & 30.0 \\
\hline Manufactura & 23.0 & 26.8 & 17.2 & 16.0 & 16.0 & 16.0 & 15.0 \\
\hline Servicios & 45.0 & 57.3 & 61.6 & 60.0 & 60.0 & 60.0 & 60.0 \\
\hline \multicolumn{8}{|l|}{ GR Andino } \\
\hline Agricultura & 17.3 & 14.3 & 12.9 & 11.0 & 10.6 & 10.3 & 10.0 \\
\hline Industria & 35.4 & 39.1 & 36.0 & 36.1 & 33.5 & 34.2 & 35.1 \\
\hline Manufactura & 17.7 & 18.8 & 17.1 & 16.1 & 15.2 & 14.8 & 14.7 \\
\hline Servicios & 47.3 & 46.7 & 51.0 & 52.9 & 55.9 & 55.5 & 54.9 \\
\hline \multicolumn{8}{|c|}{ GR MERCOSUR } \\
\hline Agricultura & 18.63 & 14.8 & 11.6 & 9.7 & 10.1 & 13.0 & 15.2 \\
\hline Industria & 34.6 & 35.5 & 30.0 & 27.0 & 29.3 & 30.2 & 31.2 \\
\hline Manufactura & 25.8 & 25.8 & 19.2 & 16.1 & 15.2 & 16.1 & 16.7 \\
\hline Servicios & 47.2 & 49.7 & 58.3 & 63.3 & 60.3 & 56.9 & 53.6 \\
\hline
\end{tabular}

Fuente: World Development Indicadors (WDI), CANSIM Elaboración: MINCETUR/VMCE/OGEE

Gráfico N.o 1. Índice de Desarrollo Humano.

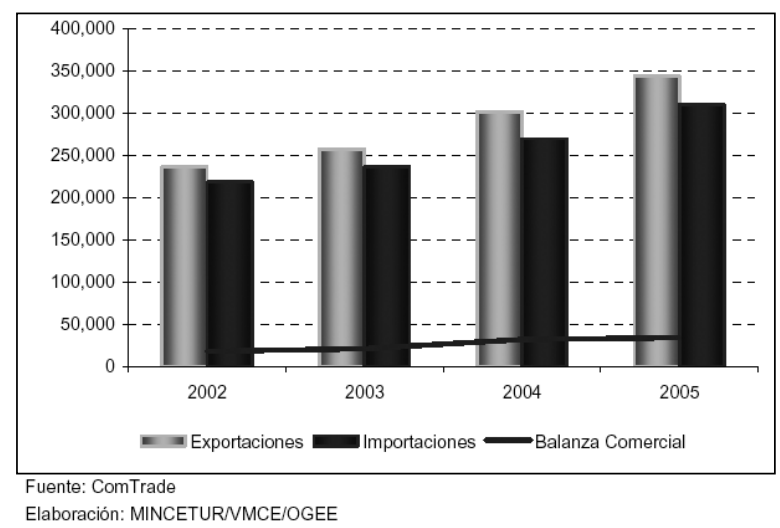




\section{Balanza Comercial}

Canadá ocupa el octavo lugar como país exportador y el noveno como importador, lo cual evidencia su importancia en el comercio internacional mundial. La Balanza Comercial de Canadá con el mundo es superavitaria; en el 2005 alcanzó los US\$ 34,093 millones.

Las exportaciones totales de Canadá alcanzaron los US\$ 343,911 millones en el 2005, con una tasa de crecimiento promedio anual igual a $7.5 \%$. Las manufacturas de alta y mediana tecnología (42.8\%) fueron los productos más exportados por Canadá.

Las importaciones totales de Canadá crecieron a una tasa promedio anual $(7.0 \%)$ menor a la de las exportaciones, registrando en el 2005 US\$ 309,818 millones. Los principales productos importados durante el 2005 fueron materias primas y bienes intermedios para la industria (24.1\%) (ver Cuadro № 2).

Las importaciones canadienses destinadas a América Latina en el 2005 ascendieron a US\$ 20,416 millones. Las materias primas y productos intermedios para la industria fue el sector con mayores importaciones seguido por bienes de consumo duradero (ver Cuadro № 3 y Gráfico № 2).

\section{Comercio de Bienes entre Perú y Canadá}

El comercio de Canadá con el Perú ha resultado favorable a nuestro país, habiéndose incrementado significativamente durante los dos últimos años debido al crecimiento de las exportaciones mineras, especialmente del oro que aumentaron en US\$ 558 millones (ver Gráfico № 3). Es de anotar que las exportaciones de oro peruano a Gran Bretaña disminuyeron.

\section{DISCUSIÓN: PERSPECTIVAS DEL TLC PERÚ- CANADA}

\section{Exportaciones}

Actualmente los exportadores peruanos compiten con los de Chile y Costa Rica en condiciones desfavorables. Si bien es cierto nos corresponde el Arancel Preferencial General, nuestros productos pagan aranceles mayores que los chilenos y costarricenses. El TLC con Canadá nos permitirá competir en igualdad.

Durante las negociaciones previas a la firma, el Gobierno del Perú elaboró un Índice de Prioridad (IP), un Nivel de Oferta (NO) y el Valor Agregado (VA) de los productos que se han de comerciar. Adicionalmente, se dividieron los

Cuadro № 2. Balanza Comercial de Canadá al 2005.

\begin{tabular}{|l|c|}
\hline \multicolumn{1}{|c|}{ Indicador } & Valor \\
\hline Población 2005 (millones) & 32 \\
\hline PBI Real 2005 (US\$ millones) & 812,279 \\
\hline Tasa de Crecimiento (\%) 1990-2005 & 2.64 \\
\hline PBI Total PPP 2005 (US\$ millones) & $1,061,236$ \\
\hline Tasa de Crecimiento (\%) 1990-2005 & 3.69 \\
\hline PBI per cápita PPP 2005 (US\$) & 34,558 \\
\hline Tasa de Crecimiento (\%) 1990-2005 & 3.69 \\
\hline PBI per cápita PPP 2005 (US\$) & 32,886 \\
\hline Tasa de Crecimiento (\%) 1990-2005 & 3.86 \\
\hline Indice de Desarrollo Humano (IDH) 2004 & 0.95 \\
\hline Inflación 2005 (\%) & 2.20 \\
\hline Exportaciones de Bienes y Servicios (\% PBI) & 46.0 \\
\hline Importaciones de Bienes y Servicios (\% PBI) & 42.0 \\
\hline Flujo de IED en Canadá 2005 (US\$ millones) & 34,610 \\
\hline Stock de IED en Canadá 2005 (US\$ millones) & 415.561 \\
\hline Flujo de IED de Canadá en el mundo 2005 (US\$ millones) & 13,620 \\
\hline Stock de IED de Canadá en el mundo2005 (US\$ millones) & 465,058 \\
\hline
\end{tabular}

Fuente: Banco Mundial, UNCTAD, CANSIM (CANADÁ)

Elaboración: MINCETUR/VMCE/OGEE 
Gráfico N.o 2. Balanza Comercial de Canadá con América Latina (en millones de dólares).

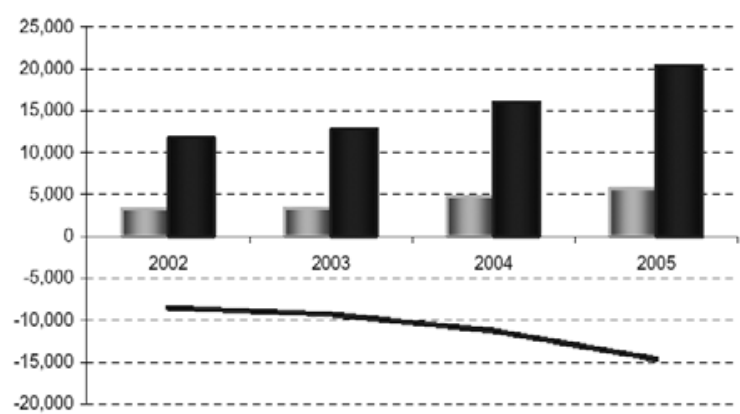

E Exportaciones Importaciones _-Balanza Comercial
Gráfico № 3 Balanza Comercial del Perú con Canadá.

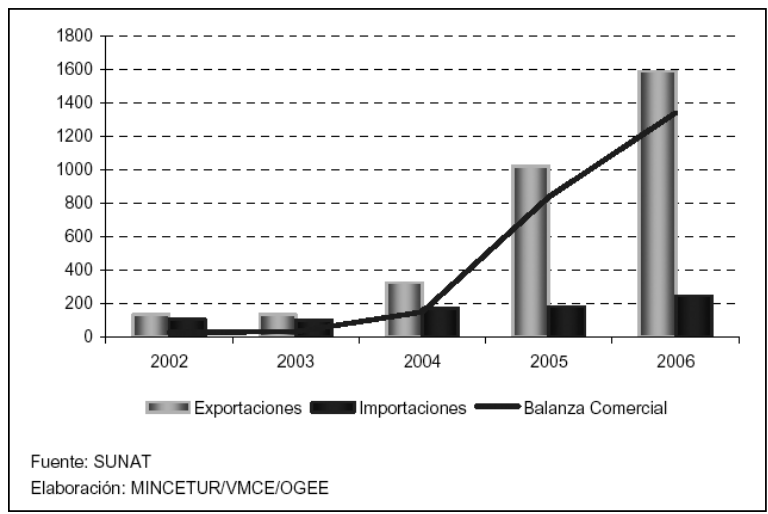

Cuadro № 3. Desagregado de las exportaciones e importaciones de Canadá según país.

Exportaciones Totales de Canadá según país de destino (US\$ millones)

\begin{tabular}{|l|r|r|}
\hline \multicolumn{1}{|c|}{ País } & \multicolumn{1}{c|}{ 2005 } & \multicolumn{1}{c|}{ Part. (\%) } \\
\hline Estados Unidos & 302,204 & 87.9 \\
\hline Japón & 7,543 & 2.2 \\
\hline Reino Unidos & 6,819 & 2.0 \\
\hline China & 5,835 & 1.7 \\
\hline México & 2,690 & 0.8 \\
\hline Alemania & 2,668 & 0.8 \\
\hline Corea del Sur & 2,319 & 0.7 \\
\hline Francia & 2,095 & 0.6 \\
\hline Bélgica & 1,880 & 0.5 \\
\hline Países Bajos & 1,811 & 0.5 \\
\hline Resto & 8,047 & 2.3 \\
\hline Total & 343,911 & 100.0 \\
\hline
\end{tabular}

Fuente: Comtrade

Elaboración: MINCETUR/VMCE/OGEE

productos con potencial de crecimiento exportador en dos categorías: los que actualmente ingresan al mercado de Canadá y los que aún no han ingresado a dicho mercado.

Los productos de los sectores agropecuario y textil cuentan con una mayor presencia en el mercado canadiense. Destacan los espárragos, las hortalizas, frutas conservadas y algunas confecciones de punto de algodón. Los productos con potencial exportador hacia Canadá son los muebles de dormitorio de madera, partes de aparatos eléctricos de alumbrado y limpiaparabrisas para automóviles.

\begin{tabular}{|l|r|r|}
\hline \multicolumn{3}{|c|}{$\begin{array}{c}\text { Importaciones Totales de Canadá según país } \\
\text { de origen (US\$ millones) }\end{array}$} \\
\hline \multicolumn{1}{|c|}{ País } & \multicolumn{1}{c|}{2005} & \multicolumn{1}{c|}{ Part. (\%) } \\
\hline Estados Unidos & 177,671 & 57.3 \\
\hline China & 24,364 & 7.9 \\
\hline Japón & 12,211 & 3.9 \\
\hline México & 12,047 & 3.9 \\
\hline Reino Unido & 8,588 & 2.8 \\
\hline Alemania & 8,477 & 2.7 \\
\hline Noruega & 5,004 & 1.6 \\
\hline Corea del Sur & 4,439 & 1.4 \\
\hline Francia & 4,122 & 1.3 \\
\hline Italia & 3,780 & 1.2 \\
\hline Resto & 49,116 & 15.9 \\
\hline Total & 309,818 & 100.0 \\
\hline
\end{tabular}

\begin{tabular}{|l|l|l|l|l}
\hline & 309,818 & 100.0 \\
\hline
\end{tabular}




\section{Políticas arancelarias canadienses}

El Arancel Preferencial General (APG) es un sistema de preferencias arancelarias otorgado por Canadá unilateralmente a la mayoría de países en desarrollo, entre los que se encuentra el Perú.

Al 2006, el 31.4\%, del universo arancelario canadiense formaban parte del APG con márgenes de preferencia que oscilaban entre el $75 \%$ y $100 \%$. De estas sub partidas, el $45.3 \%$ posee un margen de preferencia de $100 \%$. En términos generales el $99.2 \%$ de productos elegibles del APG son productos del sector no tradicional; no obstante, aquellos productos que tienen ingreso exento del pago de aranceles se concentran en los sectores metal-mecánico, químico, sidero-metalúrgico y agropecuario. Cabe resaltar que en el sector textil las preferencias son bastante restringidas ya que sólo el 23.3\% de las sub partidas textiles pueden acogerse al arancel preferencial del APG y pagar aranceles superiores al $0 \%$.

Según las estadísticas canadienses, el 1.6\% (US\$ 18 millones) de las exportaciones peruanas a Canadá podría estar ingresando con arancel preferencial siendo el sector pesquero tradicional el más beneficiado, con exportaciones que bordean los US\$ 16 millones. Por otro lado, las exportaciones de productos no tradicionales que podrían acogerse al APG sólo alcanzan los US\$ 2.5 millones (11.3\% de las exportaciones no tradicionales peruanas a Canadá); esto se debe a que el ámbito del APG no comprende productos agropecuarios y textiles que Perú exporta de manera significativa.

Sin embargo, en sus diferentes acuerdos comerciales, Canadá ha excluido algunos productos agrícolas por considerarlos sensibles. $\mathrm{Si}$ bien el número de líneas arancelarias excluidas en cada negociación varían, las categorías de productos se repiten en la mayoría de acuerdos como son las aves vivas, carne de ave, derivados de carne, productos lácteos, los huevos y sus derivados.

\section{Acuerdos para la promoción y protección recíproca}

Los Acuerdos para la Promoción y Protección Recíproca de las Inversiones (APPRI) son convenios internacionales en materia de Inversión Extranjera Directa (IED) basados en la reci- procidad, y son diseñados para el fomento y la protección jurídica de los flujos de capital. Tradicionalmente, cuando surgen disputas sobre inversión, los inversionistas extranjeros se encontraban limitados a buscar soluciones a través de las cortes domésticas del país receptor o a través de reclamos diplomáticos; sin embargo, los APPRI proveen un mecanismo para dirigir reclamos directamente al estado receptor a través de un arbitraje internacional.

Las negociaciones para el APPRI Perú-Canadá comenzaron a principios de la década del noventa, sin embargo fueron puestas en espera hasta diciembre del 2003, mientras Canadá diseñaba el nuevo Modelo APPRI 200444. El acuerdo firmado el 14 de noviembre del 2006 constituye un instrumento complementario en la política peruana para promover un mayor nivel de inversión canadiense que, de por sí, es uno de las más importantes en el área minera e industrial.

El APPRI firmado con Perú contiene tres obligaciones básicas:

- Trato no discriminatorio. El inversionista extranjero y la inversión realizada deben recibir el mismo trato que los inversionistas domésticos (trato nacional) y aquellos procedentes de otros países (trato NMF).

- Trato justo y equitativo. La inversión extranjera debe recibir un trato justo y equitativo de acuerdo a las leyes internacionales, incluyendo protección completa y seguridad.

- Compensación por expropiación. La expropiación, o medidas equivalentes a ella, deben realizarse por propósitos públicos, no discriminatorios, de acuerdo a los procesos de ley pertinentes y acompañados por un pago adecuado de compensación.

El retorno de inversiones, sin embargo, está ausente en las provisiones operativas del APPRI Perú-Canadá, incluyendo las provisiones que conciernen el trato justo y equitativo, expropiación, trato nacional y trato NMF. El APPRI Perú-Canadá limita el beneficio de los inversionistas canadienses de las obligaciones de NMF del gobierno receptor, incluyendo la posibilidad de aprovecharse de tratados más favorables negociados por Perú con terceros países. 


\section{Cooperación Internacional Canadiense}

El objetivo central de la cooperación canadiense destinada a países en vías de desarrollo es promover la generación de un proceso de desarrollo sostenible por lo cual, la cantidad de recursos que recibe cada sector, depende de su contribución en la consecución de este objetivo (ver Gráfico № 4).

Gráfico N. - 4. Recursos de cooperación por sector que destina Canadá a los países en desarrollo.

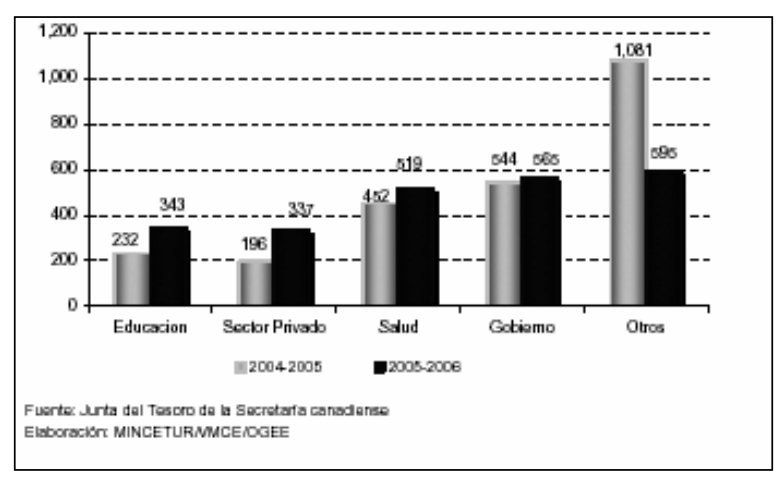

\section{CONCLUSIONES}

1. Si las condiciones de crecimiento económico del Perú se mantienen durante los próximos diez años, el Tratado de Libre Comercio entre Perú y Canadá nos brindará en el futuro un intenso intercambio comercial y cultural.

2. Debido al gran avance industrial de Canadá, el mayor beneficio para nuestro país se presenta en la transferencia tecnológica.

3. Debido a las buenas relaciones con Canadá es posible que la ayuda internacional que dicho país destinada al área educativa redunde en importantes avances en materia de alfabetización en nuestro país, así como en la mejora del nivel educativo tecnológico.

4. Debido al intercambio cultural entre ambos países, la calidad de vida de la población canadiense servirá de modelo para futuros proyectos de desarrollo social.

\section{BIBLIOGRAFÍA}

MINCETUR. Resúmenes Ejecutivos del Tratado de Libre Comercio Perú-Canadá. Primera Ronda de Negociaciones en Lima, Perú. 16 al 20 de julio del 2007

MINCETUR. Tratado de Libre Comercio Perú-Canadá. Informe Final de Negociaciones en Lima, Perú. Resumen Ejecutivo.

MINCETUR. Tratado de Libre Comercio Perú-Canadá. Segunda Ronda de Negociaciones en Ottawa, Canadá. 4 al 7 de setiembre del 2007.

MINCETUR. Tratado de Libre Comercio Perú-Canadá. Tercera Ronda de Negociaciones en Bogotá, Colombia. 30 de setiembre al 6 de octubre del 2007.

MINCETUR/VMCE/OGEE. Reporte Técnico sobre el Tratado de Libre Comercio Perú-Canadá 2007.
Páginas Web
www.mincetur.gob.pe
www.canada.org
www.canadaperu.org 